\title{
Cytochrome P4502E1 is present in rat pancreas and is induced by chronic ethanol administration
}

\author{
I D Norton, M V Apte, P S Haber, G W McCaughan, R C Pirola, J S Wilson
}

\begin{abstract}
Background-The mechanisms responsible for the initiation of alcoholic pancreatitis remain elusive. However, there is an increasing body of evidence that reactive oxygen species play a role in both acute and chronic pancreatitis. In the liver, cytochrome P4502E1 (CYP2E1, the inducible ethanol metabolising enzyme) is one of the proposed pathways by which ethanol induces oxidative stress.

Aims-To determine whether CYP2E1 is present in the pancreas and, if so, whether it is inducible by chronic ethanol feeding. Methods-Eighteen male SpragueDawley rats were pair fed liquid diets with or without ethanol as $36 \%$ of energy for four weeks. CYP2E1 levels were determined by western blotting of microsomal protein from both pancreas and liver. Messenger RNA (mRNA) levels for CYP2E1 were quantified using dot blots of total pancreatic RNA.

Results-CYP2E1 was found in the pancreas. Furthermore, the amount of CYP2E1 was greater in the pancreas of rats fed ethanol compared with controls (mean increase over controls 5.1-fold, 95\% confidence intervals 2.4 to $7.7, \mathrm{p}<0.02$ ). In the liver, induction by ethanol of CYP2E1 was similar (mean increase over controls 7.9-fold, $95 \%$ confidence intervals 5.2 to 10.6, p $<0.005)$. Pancreatic mRNA levels for CYP2E1 were similar in ethanol fed and control rats.

Conclusions-CYP2E1 is present in the rat pancreas and is inducible by chronic ethanol administration. Induction of pancreatic CYP2E1 is not regulated at the mRNA level. The metabolism of ethanol via CYP2E1 may contribute to oxidative stress in the pancreas during chronic ethanol consumption.

(Gut 1998;42:426-430)
\end{abstract}

Gastroenterology,

Prince of Wales

Hospital, Sydney,

Australia

I D Norton

M V Apte

P S Haber

G W McCaughan

R C Pirola

J S Wilson

Correspondence to:

Dr J S Wilson, Department

of Gastroenterology, Prince

of Wales Hospital, High

Street, Randwick 2031,

Australia.

Accepted for publication 5 September 1997 species have the potential to damage lipid membranes, intracellular proteins, and DNA. ${ }^{9}$ A recent study of acute ethanol administration in rats has provided evidence of oxidative stress in the pancreas as indicated by increased malondialdehyde levels as well as an increased ratio of oxidised to reduced glutathione in the pancreas of rats gavaged with ethanol compared with controls. ${ }^{10}$ Furthermore, hydroxyethyl radical (a free radical form of ethanol) has been found in the pancreas of rats chronically fed ethanol. ${ }^{11}$

Cytochrome P4502E1 (CYP2E1) is the ethanol inducible form of cytochrome P450. In heavy drinkers, this enzyme is a major pathway of ethanol metabolism. ${ }^{12}$ Chronic ethanol exposure leads to a five to 10 -fold increase in this protein within the hepatocyte. ${ }^{13}$ One consequence of the metabolism of ethanol via CYP2E1 is the formation of reactive oxygen species. ${ }^{14}$ To date, CYP2E1 has not been shown in pancreatic tissue. Therefore, the aims of this study were: (1) to determine whether CYP2E1 occurs in rat pancreas; (2) to determine whether this protein is inducible by chronic ethanol administration; and if so, (3) to determine whether this induction is accompanied by an increase in the level of messenger RNA (mRNA) for this enzyme.

\section{Materials and methods}

ANIMALS

Eighteen male weanling Sprague-Dawley rats weighing between 80 and $100 \mathrm{~g}$ were pair fed, for four weeks, either a control diet or a diet containing ethanol as $36 \%$ of energy. Control rats received an isoenergy diet with carbohydrate substituting for ethanol. The diet was prepared according to the formulation of Lieber and DeCarli. ${ }^{15}$ It had an energy density of $4.18 \mathrm{MJ} /$ litre and was supplemented with adequate amounts of vitamins and minerals. Both alcohol and control diets contained equal amounts of lipid and polyunsaturated fatty acids.

\section{ISOLATION OF MICROSOMAL PROTEIN}

Animals were killed by decapitation in the fed state. The pancreas was quickly removed and trimmed of excess fat. All procedures were performed on ice. The pancreas was minced with scissors in a homogenising solution $(1 / 50$ $\mathrm{wt} / \mathrm{vol}$ ) comprising $0.3 \mathrm{M}$ sucrose containing a combination of protease inhibitors: phenylmethylsulphonyl fluoride (PMSF, $20 \mu \mathrm{g} / \mathrm{ml}$ ), soybean trypsin inhibitor $(100 \mu \mathrm{g} / \mathrm{ml})$, leupeptin $(10 \mu \mathrm{g} / \mathrm{ml})$, and benzamidine $(20 \mu \mathrm{g} / \mathrm{ml})$. The tissue was then homogenised, firstly using an Ultra Turrax homogeniser (Janke and Kunkel, Germany) for 30 seconds and then with four strokes of a Potter S homogeniser (B Braun, Australia) at $1300 \mathrm{rpm}$.

The liver was perfused with $50 \mathrm{ml}$ iced saline via the portal vein to wash out excess blood and then removed. After weighing, a piece of liver 
was homogenised using the same protocol as for the pancreas.

Liver and pancreatic microsomes were prepared using the method of Meldolesi et al. ${ }^{16}$ Using a Sorvall RC-5B centrifuge with an SS-34 rotor (DuPont, Wilmington, Delaware), crude homogenate was centrifuged at $1000 \mathrm{~g}$ for 10 minutes to remove unbroken cells and nuclear debris. The supernatant was then centrifuged at $12500 \mathrm{~g}$ for 10 minutes and the pellet discarded. Using a Beckman L8-70M ultracentrifuge with an SW-41 rotor (Beckman Instruments, Palo Alto, California), the resulting supernatant was centrifuged at $27000 \mathrm{~g}$ for 10 minutes to sediment the rough endoplasmic reticulum. The subsequent supernatant was centrifuged for one hour at $109000 \mathrm{~g}$ to yield a fraction rich in smooth endoplasmic reticulum (microsomes). ${ }^{16}$ All procedures were performed at $4^{\circ} \mathrm{C}$. The $109000 \mathrm{~g}$ pellet was resuspended in homogenising solution and stored at $-70^{\circ} \mathrm{C}$ for further analysis. Microsomal protein was determined by the method of Lowry et al. ${ }^{17}$

\section{IDENTIFICATION OF CYP2E1}

Microsomal proteins from pancreas and liver (50 and $1.25 \mu \mathrm{g}$, respectively) were separated by electrophoresis (in $12.5 \%$ polyacrylamide gel) using Biorad Minigel apparatus (Biorad Laboratories, Richmond, California). Protein migration was assessed using protein standards (Kaleidoscope, Biorad). Protein bands were transferred to a nitrocellulose membrane (Hoffer Scientific, San Francisco, California) using an IMM-1 semi-dry blotter (WEP Instruments, Seattle, Washington) at $80 \mathrm{~mA}$ for 90 minutes. The membrane was blocked with $5 \%$ skimmed milk in Tris buffered saline (TBS, $\mathrm{pH}$ 7.6) for one hour and incubated overnight with a polyclonal rabbit antirat CYP2E1 antibody $(1 / 1000$, in $5 \%$ skimmed milk in TBS). Following incubation with primary antibody, membranes were washed in TBS and incubated for one hour with secondary antibody (donkey antirabbit antibody, Amersham, UK; 1/1000 in TBS). CYP2E1 bands were detected on radiographic film (Eastman Kodak, Rochester, New York) using enhanced chemiluminescence (ECL, Amersham). Bands were quantified via videodensitometry (Tracktel, Vision Systems, Australia) and CYP2E1 levels were expressed in arbitrary densitometer units.

ANALYSIS OF RNA

Pancreatic RNA was isolated by a modification of the method of Chomczynski and Sacchi ${ }^{18}$ as previously described ${ }^{19}$ using a frozen portion of the gland.

Analysis of messenger RNA

Analysis of CYP2E1 messenger RNA was performed qualitatively via northern blotting and quantitatively via dot blotting according to previously published methods. ${ }^{18}$ CYP2E1 mRNA was detected using a 1.2 kilobase cDNA probe. This probe was radiolabelled with ${ }^{32} \mathrm{P}$ deoxycytosine triphosphate using a random priming kit (Megaprime labelling systems, Amersham, UK). Unincorporated nucle- otides were removed using nucleic acid purification columns (NENSORB 20, DuPont). Labelling typically resulted in $5-7 \times 10^{8} \mathrm{cpm} / \mu \mathrm{g}$ DNA.

An oligonucleotide probe for $\beta$ actin (5' CT CGTCATACTCCTGCTTGCTGATC 3') was used as an internal control to ensure equal loading for both northern and dot blots. This probe was labelled with a $5^{\prime}$ end labelling kit (NEN oligonucleotide end labelling kit, DuPont).

\section{Prehybridisation and hybridisation}

When using the cDNA probe for CYP2E1, blots were prehybridised in a solution containing: $5 \times$ sodium chloride sodium citrate (SSC), $0.025 \mathrm{~mol} / 1$ sodium phosphate buffer ( $\mathrm{pH} 7.0$ ), $0.1 \%$ sodium dodecyl sulphate (SDS), 0.5 $\mathrm{mg} / \mathrm{ml}$ salmon sperm DNA, and $5 \times$ Denhardt's solution. Prehybridisation was carried out at $65^{\circ} \mathrm{C}$ for one hour. The cDNA probe for CYP2E1 was then added at a final concentration of $1 \times 10^{6} \mathrm{cpm} / \mathrm{ml}$ of prehybridisation mix. Membranes were hybridised overnight at $65^{\circ} \mathrm{C}$ and membranes were then washed with $1 \times$ SSC, $0.1 \%$ SDS for 30 minutes at room temperature, followed by four washes $(2 \times 30$ minutes, $1 \times 60$ minutes, and $1 \times 30$ minutes) in $0.2 \% \mathrm{SSC}, 0.1 \% \mathrm{SDS}$ at $65^{\circ} \mathrm{C}$. Prehybidisation, hybridisation, and washing conditions for the $\beta$ actin probe were as previously described. ${ }^{19}$

\section{Autoradiography and densitometry}

Northern blots were exposed to autoradiography film at $-70^{\circ} \mathrm{C}$ for 48 hours. Quantitation of dot blots for CYP2E1 was determined using a microchannel array detector (InstantImager, Packard Instruments, Downers Grove, Illinois) for 12 hours. Autoradiographs of dot blots for $\beta$ actin were quantified by videodensitometry (vide supra).

\section{MATERIALS}

All chemicals were of analytical grade and purchased from the Sigma Chemical Company (St Louis, Missouri). ${ }^{32} \mathrm{P}$ dCTP was purchased from Amersham. Molecular biology reagents were purchased from Biorad Laboratories. Anti-CYP2E1 antibody was kindly donated by Professor Magnus Ingelman-Sundberg, Karolinska Institute, Stockholm, Sweden, the 1.2 kilobase CYP2E1 cDNA probe was kindly donated by Dr Maurice Veronese, Flinders University, Adelaide, Australia, and the $\beta$ actin probe was kindly donated by Dr Alex Bishop, Royal Prince Alfred Hospital, Sydney, Australia.

\section{STATISTICAL ANALYSIS}

Western blot data were expressed as a relative increase compared with control with $95 \%$ confidence intervals. RNA data were expressed as means (SEM). Student's $t$ test for paired samples was used to determine statistical significance between groups. Analyses were performed using the Statview II statistical program. 
Table 1 General characteristics

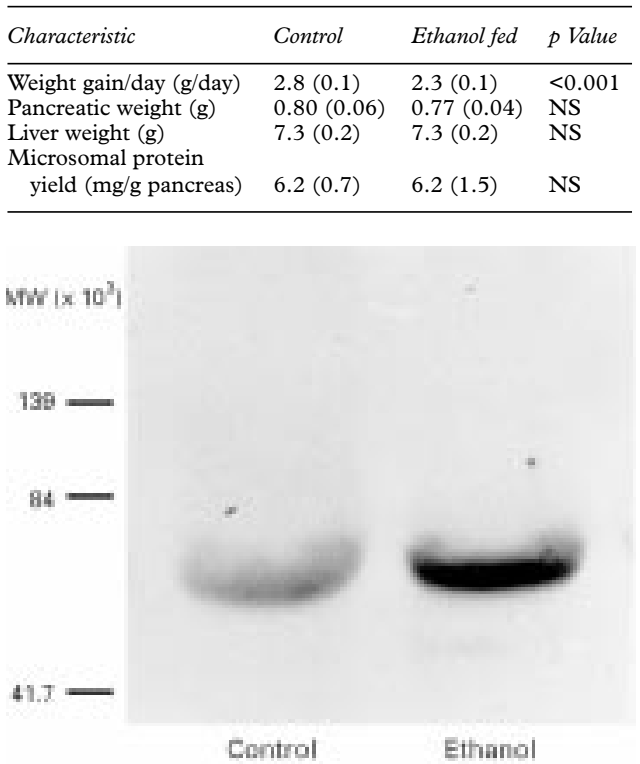

Figure 1 Representative western blot of pancreatic microsomal protein showing the presence of cytochrome P4502E1 in control pancreas and induction of this protein due to chronic ethanol administration.

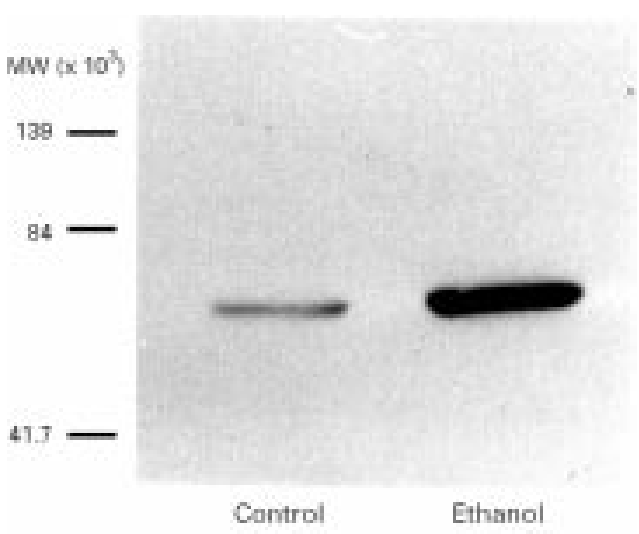

Figure 2 Representative western blot of hepatic microsomal protein showing the presence of cytochrome P4502E1 in control liver and induction of this protein due to chronic ethanol administration.

ETHICS APPROVAL

This project was approved by the Animal Care and Ethics Committee of the University of New South Wales.

\section{Results}

GENERAL PARAMETERS

All animals remained well for the duration of feeding. The rate of weight gain was slightly less in ethanol fed animals (table 1), in accord with the relative inefficiency of ethanol derived calories. ${ }^{20}$ Pancreatic weights were similar in both groups.

PANCREATIC CYP2E1

western blots of pancreatic microsomal protein from control rats showed a single band (56000 daltons), corresponding to the known molecular weight of CYP2E1 (fig 1).

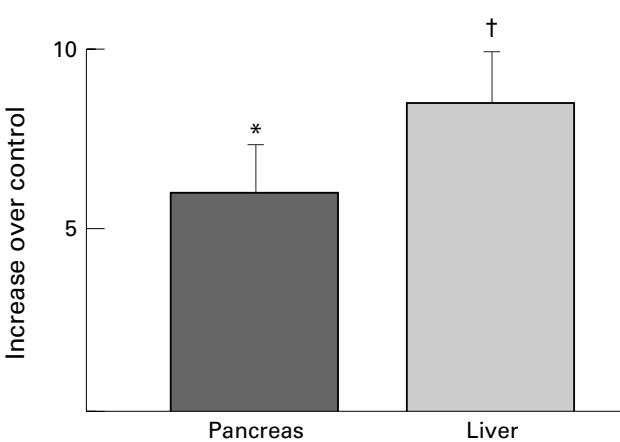

Figure 3 Induction of CYP2E1 in pancreas and liver of rats fed ethanol. Results expressed as $x$ fold increase over control, calculated from arbitrary densitometer units per $\mu \mathrm{g}$ of microsomal protein. $n=9$ pairs. ${ }^{\star} p<0.02, t p<0.005$ compared with control.

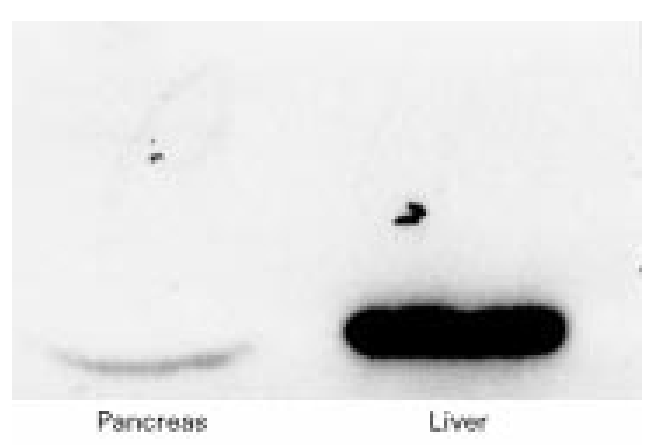

Figure 4 Representative western blot comparing the induction of CYP2E1 in the pancreas and liver during chronic ethanol exposure.

INDUCTION OF CYP2E1 IN RESPONSE TO CHRONIC ETHANOL ADMINISTRATION

The administration of ethanol led to induction of CYP2E1 in the pancreas (fig 1) with a mean increase of 5.1 -fold over controls (95\% confidence intervals 2.4 to $7.7, \mathrm{p}<0.02$; fig 3 ). The induction of CYP2E1 in the liver (fig 2) was similar to that of the pancreas, 7.9-fold over controls (95\% confidence intervals 5.2 to 10.6 , $\mathrm{p}<0.005$; fig 3). Based on the amounts of protein loaded per well, and densitometry results, there was approximately $1 / 150$ the amount of CYP2E1 in the pancreas compared with the liver per $\mu \mathrm{g}$ of microsomal protein (fig 4).

MESSENGER RNA LEVELS FOR PANCREATIC CYP2E1 Northern hybridisation (fig 5) showed that the mRNA for CYP2E1 was of the expected size. Figure 6 shows representative dot blots of RNA probed for CYP2E1 from control and ethanol fed animals. Quantitation of the dots showed that CYP2E1 mRNA levels in ethanol fed rats were similar to controls (894 (95) versus 829 (65) counts per 12 hours, $p=0.5$; figs 6 and 7). Reprobing of dot blots for $\beta$ actin mRNA showed that there was equal loading of RNA from both control and ethanol fed animals.

\section{Discussion}

This study has shown for the first time that CYP2E1 is present in the pancreas of rats and is induced in response to chronic ethanol administration. The degree of this induction is similar to that seen in the liver in this model. 

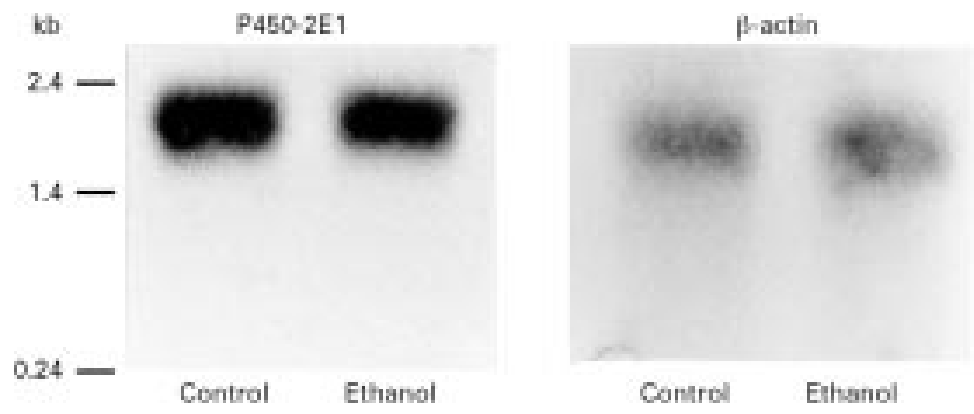

Figure 5 Representative autoradiographs of northern blots for $\beta$ actin and P4502E1 $m R N A$ showing specificity of the probes.
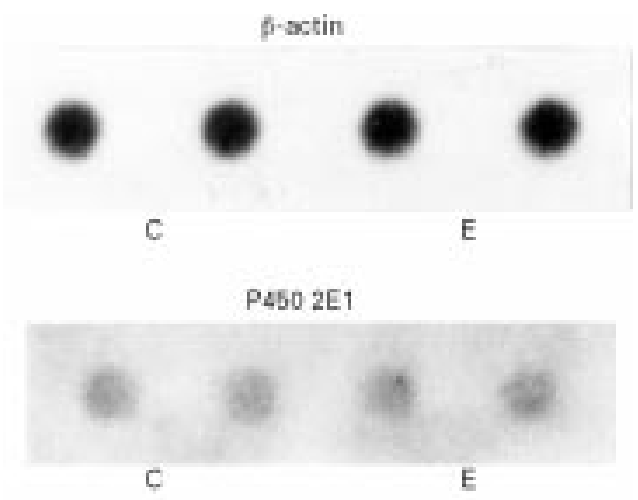

Figure 6 Representative autoradiographs of RNA dot blots from control (C) and ethanol fed (E) animals.

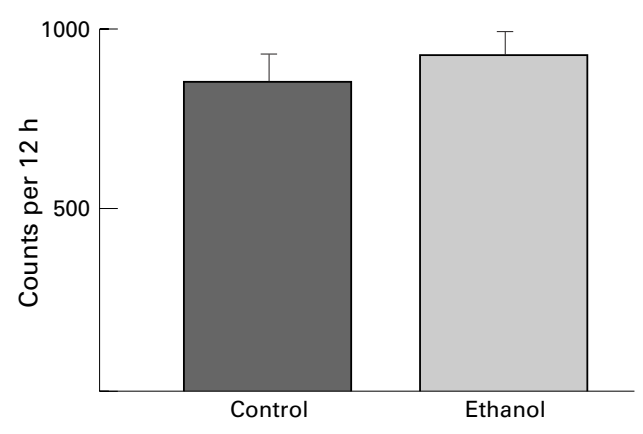

Figure 7 Comparison of CYP2E1 mRNA dot blots, determined by microchannel array detection. $n=8$ pairs (NS).

Cytochrome P4502E1 is an isoform of cytochrome P450 induced during chronic ethanol consumption. ${ }^{21}$ In the liver, the metabolism of ethanol by this enzyme system leads to the generation of reactive oxygen species. Indices of oxidative stress (increased oxidised to reduced glutathione ratio and increased lipid peroxidation products) have been shown in the livers of animals chronically fed ethanol. ${ }^{22}$ Furthermore, studies of ethanol metabolism by isolated hepatic microsomes have shown the generation of reactive oxygen species-a process which is inhibited by prior addition of antiCYP2E1 antibodies. ${ }^{14}$

It should be emphasised that CYP2E1 is not the only possible mechanism for ethanol induced oxidative stress in the pancreas. Altomare et al have hypothesised a role for acetaldehyde mediated reduction in glutath- ione in the pancreas of rats fed ethanol. ${ }^{10}$ Acetaldehyde can be generated by a number of enzyme systems in diverse cellular compartments: alcohol dehydrogenase in the cytosol, catalase in peroxisomes, and CYP2E1 in the endoplasmic reticulum. ${ }^{23}$

In the pancreas, reactive oxygen species have been implicated both in experimental ${ }^{24}$ and clinical pancreatitis. ${ }^{1-4}$ Animal models of acute pancreatitis have shown evidence of oxidative stress (increased oxidised to reduced glutathione ratio $^{6}$ and increased lipoperoxides ${ }^{8}$ ). Moreover, pretreatment with antioxidants has been shown to reduce the severity of pancreatitis in these models. ${ }^{25} 26$

Evidence of oxidative stress has been shown in the pancreas of patients with chronic pancreatitis, ${ }^{27}$ and an improved outcome with antioxidant therapy has been reported, in the form of reduced mortality in patients with acute haemorrhagic pancreatitis ${ }^{3}$ and reduced pain in patients with chronic pancreatitis. ${ }^{4}$ Furthermore, patients with idiopathic chronic pancreatitis have been shown to have decreased blood antioxidant levels. ${ }^{1}$ These studies suggest that the balance between oxidative stress and antioxidant defence mechanisms may be important in the pathogenesis of pancreatitis.

Only a minority of alcoholics develop clinical pancreatitis, ${ }^{28}$ raising the possibility that some factor predisposes a subgroup of heavy drinkers to the disease. To date, the reason for this individual susceptibility remains obscure, despite investigations of genetic factors such as $\alpha_{1}$ antitrypsin phenotype, blood group antigens, HLA antigens, and environmental factors such as type and pattern of alcohol consumption, dietary and nutritional factors, and smoking. ${ }^{29}$ With regard to CYP2E1, a polymorphism in the CYP2E1 gene has been described which results in increased transcription of the enzyme. ${ }^{30}$ This could lead to increased metabolism of ethanol via this pathway resulting in increased oxidative stress in these individuals. An association between this polymorphism and alcoholic liver disease has been reported. ${ }^{31}{ }^{32}$ Studies examining a possible link between this polymorphism and alcoholic pancreatitis are currently underway.

Braganza has hypothesised that chronic pancreatitis results from cumulative damage by reactive oxygen species formed during the metabolism of xenobiotics by cytochrome P450. ${ }^{33} 34$ To date, this hypothesis has not focused on CYP2E1, but on the induction of other isoforms of cytochrome P450 such as the $3 \mathrm{~A}$ series and $1 \mathrm{~A} 2 .{ }^{35}$ Ethanol is not a substrate for these latter isoforms of cytochrome P450, nor does chronic ethanol administration result in their induction.

In this study, messenger RNA levels for CYP2E1 in the pancreas were similar in control and ethanol fed rats. This suggests that induction of CYP2E1 in the pancreas is due either to decreased degradation of the protein product or to increased translational efficiency. These findings are similar to those observed in the liver of rats chronically fed ethanol, where increased translational efficiency ${ }^{36}$ and protein 
stabilisation $^{37}$ have both been found to be modes of induction of CYP2E1.

It is clear that the pancreatic level of CYP2E1 is substantially lower than that of the liver, suggesting that pancreatic CYP2E1 contributes little to total body ethanol metabolism. Nonetheless, within an individual pancreatic cell, CYP2E1 could generate free radicals during chronic ethanol exposure, leading to accumulation of damage to organelle membranes and intracellular proteins.

In conclusion, this study has shown for the first time that CYP2E1 is present in the rat pancreas and is induced in response to chronic ethanol exposure. These observations may be relevant to the pathogenesis of alcoholic pancreatitis.

1 Braganza JM, Schofield D, Snehalatha C, et al. Micronutrient antioxidant status in tropical compared with temperate zone chronic pancreatitis. Scand $f$ Gastroenterol 1993;28:1098-104.

2 Braganza JM, Scott P, Bilton D, et al. Evidence for early oxidative stress in acute pancreatitis. Int F Pancreatol 1995;17: 69-81.

3 Whitely GSW, Scott PD, Sharer NM, et al. Combined antioxidant and surgical approach to extensive haemorrhagic pancreatic necrosis [abstract]. Gastroenterology 1993;104: A343.

4 Whitely GSW, Kienle APB, McCloy RF, et al. Long-term pain relief without surgery in chronic pancreatitis: value of antioxidant therapy [abstract]. Gastroenterology 1993;104: A343.

5 Schoenberg S, Buchler M, Younes M, et al. Effect of antioxidant treatment in rats with acute hemorhagic pancreatitis. Dig Dis Sci 1994;39:1034-40.

6 Neuschwander TB, Ferrell LD, Sukhabote RJ, et al. Glutathione monoethyl ester ameliorates caeruleininduced pancreatitis in the mouse. 7 Clin Invest 1992;89. 109-16.

7 Sanfrey H, Bulkly GB, Cameron JL. The role of oxygen-derived free radicals in the pathogenesis of acute pancreatitis. Ann Surg 1984;200:405-13.

8 Schoenberg $\mathrm{MH}$, Buchler M, Gaspar M, et al. Oxygen free radicals in acute pancreatitis of the rat. Gut 1990;31:1138radical

9 Gonzales FJ. The molecular biology of the cytochrome P450s. Pharmacol Rev 1989;40:243-88.

10 Altomare E, Grattagliano G, Palmieri V, et al. Acute ethanol administration induces oxidative changes in rat pancreatic tissue. Gut 1996;38:742-6.

11 Iimuro Y, Bradford BU, Gao W, et al. Detection of alpha-hydroxyethyl free radical adducts in the pancreas after chronic exposure to alcohol in the rat. Mol Pharmacol 1996;50:656-61.

12 Lieber CS, DeCarli LM. The role of the hepatic microsomal oxidising system (MEOS) for ethanol metabolism in vivo. $\mathcal{F}$ Pharmacol Exp Ther 1972;181:279-87.

13 Johansson I, Ekstrom G, Scholte B, et al. Ethanol-, fasting-, and acetone-inducible cytochromes P-450 in rat liver: regulation and characteristics of enzymes belonging to the IIB and IIE gene subfamilies. Biochemistry 1988;27:1925-

14 Ekstrom G, Ingelman-Sundberg. Rat liver microsomal NADPH-supported oxidase activity and lipid peroxidation dependent on ethanol-inducible cytochrome (P450IIE1). Biochem Pharmacol 1989;38:1313-9.
15 Lieber CS, DeCarli LM. The feeding of alcohol in liquid diets. Alc Exp Clin Res 1986;10:550-3.

16 Meldolesi J, Jamieson JD, Palade GE. Composition of cellular membranes in the pancreas of the guinea pig. 3. Enzymatic activities. $\mathcal{F}$ Cell Biol 1971;49:150-8.

17 Lowry OH, Rosebrough NF, Farr AG, et al. Protein measurement with the Folin phenol reagent. $f$ Biol Chem 1951;193:265-75.

18 Chomczynski P, Sacchi N. Single-step method of RNA isolation by acid guanidinium thiocyanate-phenol-chloroform extraction. Anal Biochem 1987;162:156-9.

19 Apte MV, Wilson JS, McCaughan GW, et al. Ethanolinduced alterations in messenger RNA levels correlate with glandular content of pancreatic enzymes. $7 \mathrm{Lab}$ Clin $\mathrm{Med}$ 1995; 125:634-40.

20 Lieber CS, DeCarli LM, Sorrell MF. Experimental methods of ethanol administration [review]. Hepatology 1989;10: $501-10$

21 Tsutsumi M, Lasker JM, Shimizu M, et al. The intralobular distribution of ethanol-inducible P450IIE1 in rat and human liver. Hepatology 1989;10:437-46.

22 Teare JP, Greenfield SM, Watson D, et al. Lipid peroxidation in rats chronically fed ethanol. Gut 1994;35:1644-7.

23 Lieber CS. Metabolism of ethanol. In: Lieber CS, ed. Medical and nutritional complications of alcoholism. New York: Plenum, 1992:1-35.

24 Schoenberg MH, Buchler M, Beger HG. Oxygen radicals in experimental acute pancreatitis [review]. Hepatogastroenterology 1994;41:313-9.

25 Niederau C, Niederau M, Borchard F, et al. Effects of antioxidants and free radical scavengers in three different models of acute pancreatitis. Pancreas 1992;7:486-96.

26 Sanfrey H, Sarr MG, Bulkley GB, et al. Oxygen-derived free radicals and acute pancreatitis: a review. Acta Physiol Scand 1986;548:109-18.

27 Schoenberg MH, Buchler M, Pietrzyk C, et al. Lipid peroxidation and glutathione metabolism in chronic pancreatitis. Pancreas 1995;10:36-43.

28 Steinberg W, Tenner S. Acute pancreatitis [review]. $N$ Engl f Med 1994;330:1198-210.

29 Haber P, Wilson J, Apte M, et al. Individual susceptibility to alcoholic pancreatitis: still an enigma [review]. $\mathcal{F}$ Lab Clin Med 1995;125:305-12.

30 Hayashi S, Watanabe J, Kawajiri K. Genetic polymorphisms in the 5 ' flanking region change transcriptional regulation of the human cytochrome P4502E1 gene. F Biochem 1991; 110:559-65.

31 Kato S, Onda M, Matsukura N, et al. Cytochrome P4502E1 (CYP2E1) genetic polymorphism in a case-control study of gastric cancer and liver disease. Pharmacogenetics 1995;5: S141-4.

32 Pirmohamed M, Kitteringham NR, Quest LJ, et al. Genetic polymorphism of cytochrome P4502E1 and risk of alcoholic liver disease in Caucasians. Pharmacogenetics 1995;5:351-7.

33 Uden S, Acheson DW, Reeves J, et al. Antioxidants, enzyme induction, and chronic pancreatitis: a reappraisal following studies in patients on anticonvulsants. Eur 7 Clin Nutr 1988;42:561-9.

34 Guyan PM, Uden S, Braganza JM. Heightened free radical activity in pancreatitis. Free Rad Biol Med 1990;8:347-54.

35 Foster JR, Idle JR, Hardwick JP, et al. Induction of drug-metabolizing enzymes in human pancreatic cancer and chronic pancreatitis. F Pathol 1993;169:457-63.

36 Song BJ, Veech RL, Park SS, et al. Induction of rat hepatic $\mathrm{N}$-nitrosodimethylamine dimethylase activity by acetone is due to protein stabilisation. $f$ Biol Chem 1989;264:356872 .

37 Kim SG, Novak RF. Induction of rat hepatic P450IIE1 (CYP 2E1) by pyridine: evidence for a role of protein synthesis in the absence of transcriptional activation. Biochem Biophys Res Commun 1990;166:1072-9. 